\title{
Study on Marketing Strategy Model of City Brand in Internet + Era
}

\author{
Zhao Kai, Tan Bei \\ Chongqing Technology And Business Institute , 400067,Chongqing, China \\ Chongqing Radio\&TV University, 400052, Chongqing, China
}

Keywords: City Brand; Marketing Strategy ModelInternet +; New initiatives;

\begin{abstract}
The trend of world economic integration is becoming more and more intensified, and the competition among cities and even between countries is becoming increasingly fierce. As a regional exclusive public goods, urban brands can show the charm of the region in a concentrated manner. It helps the city to accumulate competitive advantages under the regional competitive environment. It is the focus of painstaking efforts by local governments. The traditional city brand marketing in efficiency, timeliness cannot meet the requirements of the new era. This work puts forward the popularization of universal access under the environment of Internet + and the new normal of current economic development as a new opportunity for brand marketing in local cities. Under the premise of having a good historical and current status basis and defining the orientation of urban development, with a series of new initiatives can be carried out efficiently.
\end{abstract}

\section{Introduction}

Modern technology has been able to use a variety of means to gather a lot of information and produce various types of multimedia data. With the rapid expansion of multimedia information on the internet, more and more people are exposed to variety of multimedia information. Visual information includes image information, video information, image sequence information and computer graphics and animation information. The largest multimedia information is the most important image information, an image-based study multimedia services has become a hot topic in information technology [1].

City marketing is actually taking a city as an enterprise, as well as the city owned by the various resources as a business. The city brand is the core concept that a city conveys to the public and is recognized by the society in the process of establishing its own image of civilization according to its development strategy. Urban branding is a process of planning the urban development mode, development direction and economic structure and layout. The purpose is to find out the core value of urban development and the motivation of sustainable development. The purpose of urban branding is to find out the factors of sustainable development in urban development and the core values of urban development, the mode of development and the industrial structure of the whole city. For a city, an accurate strategic positioning of the city and an appropriate method of communication and promotion can help the city to create a good overall image and brand awareness of the city, comprehensively enhance the city's comprehensive competitiveness[2].

\section{Connotation and Mode of City Brand Marketing}

City brand marketing is to give full play to the overall function of the city as the starting point, by establishing a unique city image, enhance the visibility of the city, so as to meet the needs of enterprises and the general government, public management activities and processes.. Its meaning should include the foothold of urban marketing and the nature of urban marketing. The overall function refers to the city's political, economic, social and cultural functions. Marketing is not only an activity aimed at economic development,but also a comprehensive social activity in many aspects 
such as political stability, economic development, cultural creation and social resource allocation. The practice of urban marketing depends on the overall function of the city to play, the overall function of the city is to play a quiet city foothold and destination. The inner ability of the city is the collection of the urban cultural environment, industrial structure, government and so on.

Urban marketing is the top-down strategy of city government to adapt to the changing environment of urban development, which is prominently manifested as the promotion role of urban mayors. As a kind of government behavior, city marketing is in the government to realize the drawbacks of traditional city construction and management, take the initiative to provide institutional innovation to mobilize all aspects of society to participate in city construction and development of the enthusiasm of the product, a step by step development is carried on under the guidance and control of the government.The step-by-step development of urban marketing is also carried out by government . although urban marketing emphasizes the role of market mechanism and introduces market competition mechanism in marketing, it is essentially a means for the government to build and manage the city and give full play to its functions[3].

According to the system point of view, urban marketing should generally follow the process of urban environmental analysis, urban strategic positioning, urban strategic planning, urban planning and urban marketing activities. Environmental analysis combines the contents of local audits and market planning, the analysis process is shown in Figure 1:

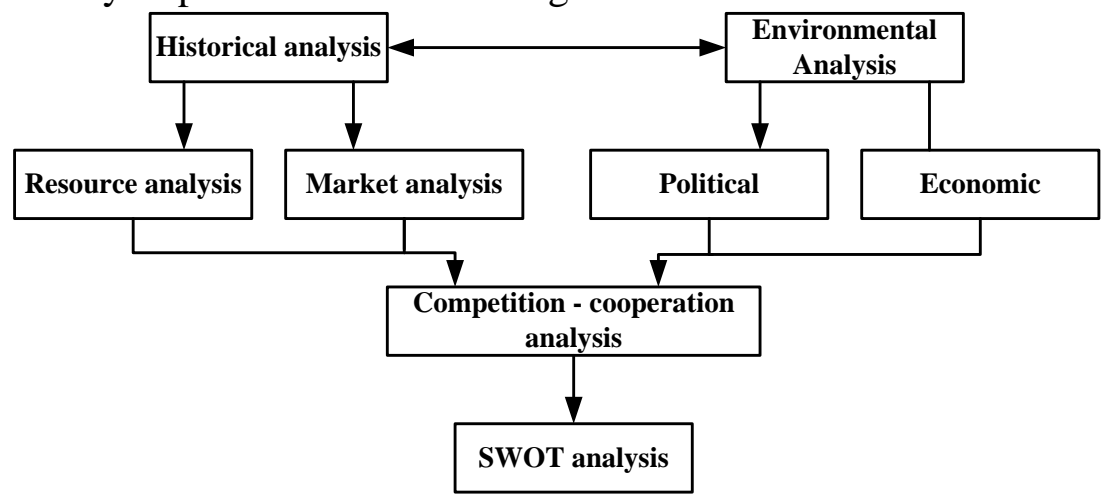

Figure.1 Environmental Analysis Framework

\section{Evaluation of City Brand Marketing Model}

Urban marketing should be achieved through the construction of marketing mode, and the effect of construction needs to be measured by establishing a scientific evaluation system. The ultimate goal of urban marketing is to make the city get more resources for the development of useful, to create a good public environment, increase urban service functions and improve the overall competitiveness of the city. Through the "functional system" and "Star Arrow model" to analyze and evaluate the rate of return on urban marketing government[4].

Due to the different dimensions of the index data of urban competitiveness. Therefore, for a comprehensive integration of these indicators, all indicator data must be dimensionless. Objective indicators are divided into single objective indicators and comprehensive objective indicators. For the dimensionless processing of original data of single objective index, this work mainly adopts three methods: standardization, indexing and threshold method. The standardization formula is[5-6]:

$$
X_{i}=\frac{X_{i}-\bar{x}}{Q^{2}}
$$

Where, $x_{i}$ : Raw data;

$\bar{x}$ :Average value;

$Q^{2}:$ Variance;

Calculation of index method is as follows; 


$$
X_{i}=\frac{x_{i}}{x_{0 i}}
$$

Where, $x_{i}$ : Raw data;

$x_{0 i}$ :The maximum value;

$X_{i}:$ Index;

Marketing effectiveness of the threshold method is calculated as follows[7]:

$$
X_{i}=\frac{x_{\max }-x_{i}}{x_{\max }-x_{\min }}
$$

$X_{i}$ :Converted value;

$x_{\max }$ :The largest sample value;

$x_{\min }$ :The minimum sample value;

$x_{i}$ : Raw data;

In the analysis of marketing effectiveness, the principal component analysis can generally be used. The principal component analysis in the quantitative statistics was originally used to deal with the component-related problems of the multi-dimensional random variables under the linear transformation. Eigenvalue is greater than or equal to percentage (100\% for urban competitiveness and $92 \%$ for each component of urban competitiveness), we decide to choose the principal component of individual values. According to the weighted sum of the eigenvalues of these principal components, a city's competitiveness or component index is constructed. One of the index of competitiveness is built by principal component analysis. The negative value here does not represent its competitiveness, but it means that the relative position of the city is below the average level.

\section{City brand marketing model in Internet + Era}

The blog or Twitter form under the Internet + is one of the main modes of city brand marketing. Weibo or Twitter is successful, thanks to its own characteristics. Weibo has an open information architecture, a large selection of third-party tools, and a large detonation capability, that is, viral marketing, which can maintain active interaction with fans in multiple functions of forwarding, likes, comments, private messages. And Twitter has the advantage of brand marketing, the survey shows that Twitter's push effect is 3 times that of Facebook,from the Twitter user base you can see it's professional. Daily active users on Twitter is a group of people: $72 \%$ of users blog at least once a month, 70\% respond to others' blogs, $61 \%$ write at least one product/consumer review per month, and $56 \%$ of users write articles for third-party websites, $53 \%$ of users publish videos online, and $50 \%$ of users help to revise Wikipedia entries. Active users on Twitter attribute themselves to the category of "hopefully influencing others.".This is why the brand marketing effectiveness under the Twitter platform is significant.

City Marketing under Internet + has three salient features: First, the marketing theme needs to be innovative. Innovation refers to the existing mode of thinking is different from the conventional or ordinary thinking ideas as the guide, the use of existing knowledge and material, in a particular environment, in line with the needs of the ideal or to meet the needs of society, to improve or create new things, methods, elements, paths, environment, and can get some beneficial effects. As urban marketing, innovation is the soul of marketing, leaving the innovation to lose its vitality. Second, urban marketing needs to create detonating hot spots. The internet platform acts like a neuron, activating the neural haptic to awaken the mechanism of life, as well as a pond of hydrostatic water that needs to be put into rocks to create ripples. Third, urban marketing needs to be hot. Hot discussion is to form a broad participation in the interaction, in order to extend the theme of vitality. Internet platforms are vast, any lack of innovative marketing programs if not cause for concern, it will quickly submerged in a huge amount of information, only detonated topics, the formation of hot spots, 
to stimulate public participation and interaction in order to maintain the image of each other under the network platform. City brand marketing process based on Internet + is as follows:

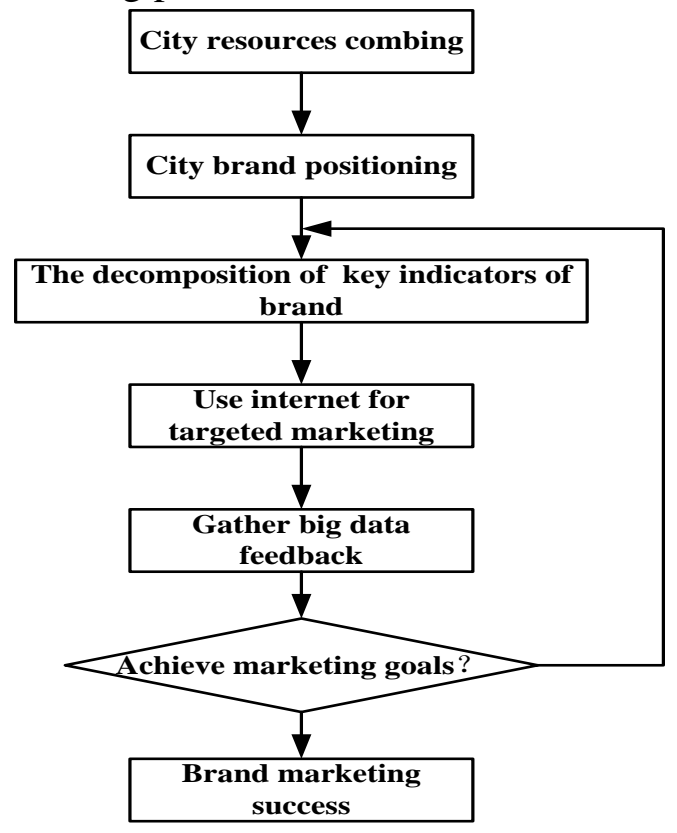

Figure.2 City brand marketing process based on Internet +

\section{Summary}

The Internet is the most important resource platform today,the key of how to operate successfully is how to use "+". As a city brand marketing, the "+" character is more reflected in the creative combination of the Internet + . From the effect point of view, the new media is more suitable for city brand marketing, which is based on its own characteristics. At the same time, we must realize that the marketing model of the city brand under the Internet + must be reflected in the mutual integration of "innovation + hot + hot discussion". Such integration must also be carried out in the the order of "innovation + hot + hot discussion",it is the only way to demonstrate the effectiveness of city brand marketing.. To sum up, the urban brand marketing model is a natural mode of development in the Internet + which is not static, it will change with the form of the Internet + . With the continuous development of the city, city brand marketing mode based on Internet + will continue to develop in depth.

\section{Acknowledgements}

This work was supported by Urban brand research on integrated marketing communication strategy ,Commissioned by the Chongqing Social Science Planning project in 2017,Project approval number:2017WT05.

\section{References}

[1] Trusov M, Bucklin R E, Pauwels K. Effects of word-of-mouth versus traditional marketing: findings from an internet social networking site[J]. Journal of marketing, 2009, 73(5): 90-102.

[2] Rust R T, Lemon K N, Zeithaml V A. Return on marketing: Using customer equity to focus marketing strategy[J]. Journal of marketing, 2004, 68(1): 109-127.

[3] Merrilees B, Miller D, Herington C. Antecedents of residents' city brand attitudes[J]. Journal of Business Research, 2009, 62(3): 362-367.

[4] Parkerson B, Saunders J. City branding: Can goods and services branding models be used to brand cities?[J]. Place branding, 2005, 1(3): 242-264.

[5] Boo S, Busser J, Baloglu S. A model of customer-based brand equity and its application to multiple destinations[J]. Tourism Management, 2009, 30(2): 219-231. 
[6] Kapferer J N. The new strategic brand management: Advanced insights and strategic thinking[M]. Kogan page publishers, 2012.

[7] Sicilia M, Palazón M. Brand communities on the internet: A case study of Coca-Cola's Spanish virtual community[J]. Corporate Communications: An International Journal, 2008, 13(3): $255-270$. 